\title{
Editorial
}

\section{RILEM Technical Letters - the new Open Access Journal of RILEM}

\author{
Johan Vyncke ${ }^{a}$, Nicolas Roussel ${ }^{b}$ \\ ${ }^{a}$ President of RILEM \\ ${ }^{\mathrm{b}}$ Editor in Chief, TAC Chair of RILEM \\ Published online: 17 March 2016 \\ (C) The Author(s) 2016. This article is published with open access.
}

Since 1947, the mission of RILEM, the International Union of Laboratories and Experts in Construction Materials, has been to advance scientific knowledge related to construction materials, systems and structures and to promote and encourage transfer and application of this knowledge worldwide. Since 1968, the peer review RILEM Journal MATERIALS \& STRUCTURES has been RILEM's flagship for disseminating the latest advances in construction materials research and structural behaviour.

With the present new scientific peer review journal, RILEM Technical Letters, RILEM seeks to venture into the new era of open access publishing by disseminating contributions breaking new ground in the field of construction materials science in the form of short letters. In particular, RILEM Technical Letters is focusing on the publication of short reports of major innovative research or strategic research needs in the field of construction materials and structures, specifically written to comply with the format of this new journal. By providing a fast publishing process, RILEM Technical Letters will constitute a new landmark among the publications devoted to construction materials science.

RILEM Technical Letters will be published as a Diamond Open Access journal available online free of charge. Publishing in open access format will allow a broad readership from all around the world to get unrestricted access to the latest knowledge in all subfields of RILEM. Moreover, RILEM will provide an additional benefit to its members by waiving publication costs if the corresponding author of the letter is a RILEM member.

On behalf of the whole RILEM community, we would like to thank the authors, reviewers and editors for their priceless contributions and wish the new journal all the success! 